\title{
Towards Understanding Collaborative Learning in the Social Media Environment
}

\author{
Mirjana Kljajić Borštnar
}

University of Maribor, Faculty of Organizational Sciences, Kidričeva 55a, 4000 Kranj, Slovenia, mirjana.kljajic@fov.uni-mb.si

\begin{abstract}
'Social media', 'Web 2.0', 'collaborative learning' and user co-creation are just some of the terms that describe changes in the role of information and communication technology (ICT) in business, private life and society. The changing face of ICT has finally brought about the fulfilment of the term 'Information Society' and made an important impact on many fields of research, including collaborative learning. The effective use of ICT in support of group collaboration has been researched and discussed. The effectiveness was attributed to systematically organized and facilitated processes. Nevertheless, the results are not always better when group support systems (GSS) are used in comparison to face-to-face work. In contrast to the well-organized GSS-supported learning process, the social media environment is non-structured, rule-free and even chaotic. In this paper, we research the possibilities of eliciting group knowledge in the group-learning process in a social media environment. A total of 24 students assigned into three groups participated in the three-week long study. Their task was to solve a given research topic by solely using an unfamiliar social media environment and to present their findings after three weeks. Students were observed in their natural learning environment (school, home, the Flowr virtual environment), and their attitudes on collaborative work using social media tools were measured with a questionnaire at the end of the study. The results suggest that non-structured social media environment stimulates self-management of the group. Some insights into trust, motivation and conflicts in the collaborative problem solving are discussed.
\end{abstract}

Keywords: social networks, collaborative problem solving, learning

\section{Introduction}

Recent developments in computer virtual communities and social media suggest that collaborative problem solving can be as or even more efficient than highly controlled computer virtual environments (Tapscott \& Williams, 2006, Barabasi, 2002, Potter, McClure, \& Sellers, 2010). To be able to use collaborative problem solving while learning in educational, organizational and inter-organizational environments, we have to understand the environment and the learning processes. Our interest is focused on how people solve complex problems, and not the optimization of it, but the understanding of how it actually happens.

From previous research on simulation-based problem solving (Škraba, Kljajić \& Leskovar, 2003; Škraba, Kljajić \& Kljajić Borštnar, 2007; Kljajić Borštnar, Kljajić, Škraba, Kofjač, \& Rajkovič, 2011), we have come to some understanding about the nature of groups working together in a computer-supported virtual environment. Specifically, in the process of complex managerial problem solving supported by a simulation model and a GSS, the role of facilitator in a group process was shown, and the group belonging effect was empirically proven (Kljajić Borštnar et al., 2011). Further, the structure of feedback information was shown to have a great impact on the performance of the group. When the individual feedback information of a simulation model efficiently supported individual learning (Škraba et al., 2003), the contribution of group information feedback was not as straightforward (Škraba et al., 2007). When group information feedback was provided in a controlled and facilitated process, it contributed to greater unity and better performance of the group members; in contrast, when it was freely accessible to the group members and the process was not facilitated, it caused the group to perform poorly and perceive the experiment poorly.

The decision process can be regarded as complex problem solving: because it is a complex cognitive process comprised of systematic processing of knowledge and rationalisation, which should minimize the possibility of making a mistake (Wang, 1997). It is being described as a learning process that should provide sufficient knowledge for efficient decision making. The basic role of information systems must be to provide the right information when needed. Nevertheless, information alone is not sufficient for successful decision making. The decision-making process often takes place in a

Received: $3^{\text {rd }}$ January 2012; revised $8^{\text {th }}$ February 2012; accepted $5^{\text {th }}$ March 2012 
social context. Decisions generated in organizational systems are not dependent on the individual decision of a subject, but rather on a group of individuals participating in decision making (i.e. experts working in a specific field). The group as a whole understands the problem better (Hale, 1997), which should lead to synergistic effects. Nevertheless, the group process is often hindered by the effects of group dynamics, such as conformity and manipulation. In the end, the quality of decision-making is difficult to evaluate and the process is bounded by the rationality of the people in it (Simon, 1991; Dubois, 2010). Group support systems are designed to manage these problems and enhance the positive effects of group work. Nevertheless, the positive effects of GSS are not unanimous in literature (Fjermestad, 2004). The problem lies in complexity of the process itself, with people as creative actors: there are problems with the level of facilitation, quantity, content, and frequency information feedback (Hsiao \& Richardson, 1999; Khalifa, Davison \& Kwok, 2002; Rouwette, Größler $\&$ Vennix, 2004). The importance of process facilitation was shown by Kljajić Borštnar et al. (2011) and Limayem, et al. (2002). Furthermore, the study of Limayem et al. (2002) reported no difference between live and computer facilitation. Kim (2010) argued that the role of a leader is turned into a facilitator and that "... facilitation encourages uncooperative members to improve their participation in order to increase group cohesiveness." (Kim, 2010: 1569); therefore, the role of a facilitator is similar to the role of a teacher.

As the effectiveness of GSS is often attributed to its systematically organized and facilitated process, with high emphasis on control, contemporary networked and open structured organizations prove to be as efficient and even more creative in generating new knowledge and problem solving without enforcing structure and facilitation. In particular, the social media and Web 2.0 environment facilitate a setting for what is called 'collective problem solving' or 'crowd sourcing' or 'social computing'. In contrast to the well-organized GSSsupported learning process, the social media environment is non-structured, rule-free and even chaotic. Social media engagement is so vast that we can find it in daily life, business; innovation, politics, science (Hafkesbrink \& Evers, 2010). The power of social media was first perceived in marketing, branding, user-oriented problem solving, and in generating public opinion. In recent years, it is seen as an opportunity to support student learning and engagement. In this context, it is important that students learn how to use social media to expand their approaches to solving problems and making decision in a collaborative ways (Minocha, 2009).

Exploring the term 'collaborative learning' takes us back to the 1990s where a large portion of research was devoted to the theme. In fact, the terms used varied considerably between authors, from 'collaborative learning' (Beckman, 1990), which is used most frequently to date, to 'peer-group learning' used by Collier (1980), 'cooperative learning' coined by Cooper (1990), and 'learning groups', researched by Fiechtner and Davis (1992). Common to all these studies was the framework of meticulously planned and engaged organization of groups (formation of groups, small number of up to five participants in groups), supporting the groups in planning and proceeding the group work, preparing instructions for group work, performing check-up of the group work, and providing help with uncooperative members. Since the 1990s many things have changed, not only the technological advances, like the emergence of the Web 2.0 participative environment, but also the changes in concepts of collaborative living, work and learning. 'Social media', 'Web 2.0', 'collaborative learning', and 'user co-creation' are just some of the terms that describe changes in the role of information and communication technology in business, private life and society. The changing face of ICT has at last fulfilled the long-used term 'Information Society' and made an important impact on many fields of research, including collaborative learning. Collaboration tools like wikis, blogs, microblogs and other so-called social media tools have influenced society as a whole and have changed the way we do things. The collaboration in a social media environment is not limited to a classroom, a set time and a small number of participants. Collaboration is considered to be any process of working with others with common objective. Similar to the description of a group learning process that may or may not result in a measurable learning outcome, but still displays the underlying group learning process (Lizeo, 2005), the collaboration process does not necessarily end up in creating values within specified spaces (Dillenbourg, 1999). This means that all collaboration tools available for supporting and promoting participative behaviour are not sufficient for the group to learn. In search of the concept of collaborative learning in the social media environment, Garrison, Anderson and Archer (2000), Freire (2000) and Wells (1999) argue that a critical discourse is of great importance within collaborative learning environments. Rosen (2007), in his book on the culture of collaboration, proposes ten cultural elements that support value creation: trust, sharing, goals, innovation, environment, collaborative chaos, constructive confrontation, communication, community, and value.

The preliminary research of collaborative problem solving phenomenon in a social media environment is presented in this paper. It is based on the assumption that collaborative learning can be efficiently supported in a rule-free and social media unstructured environment, and that it has a positive impact on the self-organizing of the group and thus contributes to problem solving and learning. Students had three weeks' time to complete the assigned study tasks using the Flowr social media (www.theflowr.com). Research was performed by observing them in the natural setting of the class conduction for the duration of three weeks. With observation methods and questionnaires, we aim to answer the following research question:

Does collaborative problem solving without formal structure and facilitation in the social media environment stimulate the self-management of the group?

\section{Methodology}

The research took place in the 'natural environment' of a Computer Systems and Communication class. The class was comprised of 45 school hours (45 minutes each) of lectures (3 weeks), followed by 30 hours of practical training in the computer classroom (two weeks). Twenty-four undergraduate 
students of the class, aged between 20 and 23 years from the Faculty of Organizational Sciences, University of Maribor, participated in the study. At the beginning of the last week of lectures, students were presented a study task (a research topic) that they had to research and present at the end of the two weeks of practical training, thereby giving them three weeks of time (one week of lectures plus two weeks of practical training). Their work on the topic was not limited to the classroom; they were free to cooperate at the time of their own choosing. They were asked to form three groups with a maximum of 10 members per group was allowed. During the study, one transition was made from Group 1 to Group 3 due to conflicts within the group, thus forming two groups of 9 and one of 6 members $\left(n_{1}=9, n_{2}=9, n_{3}=6\right)$. For the purpose of keeping the 'natural environment' intact, they were not told they were participating in a study. The role of the teacher (part of the research team) was to observe their work without interfering or facilitating it. The students were able to use the computer classrooms, but were also allowed to work from home or any facility and at time of their choice. Their task was to create a presentation of the research on topic selected by an individual group. Groups were given four topics from the class curriculum to choose from: 1) cloud computing, 2) collective problem solving, 3) information security, and 4) virtualization. The three groups selected the first three research topics.

Students received simple written and oral guidance for their assignment, explaining that they had to create groups that would research the selected topics, using the social collaboration service Flowr (www.theflowr.com). The instructions included instructions on how to use the Flowr service, and a description of the problem and the task. The task was part of the class curriculum; the topics are changed yearly according to the state of the art in the ICT field. The only new factor for the students was the use of a previously non-familiar social service.

Flowr is a web-based social media service addressing the professional communities. It offers collaboration tools, communication (microblogging, commenting, creating knowledge bases), sharing files, videos, integrating Google Apps (Gmail, Google Docs, Google Calendar), and offering tools like Bookmarklet, the Flowr Mobile App, sharing from email, multilingual support and built-in analytics. The use of Flowr basic for small groups is free of charge. Their initial task was to register at the Flowr site, form groups and start using the solution. As stated, they were free to use Flowr in any way they wanted, bearing in mind the goal: to create a critical presentation of the selected research topic. The role of the teacher (researcher) was to follow the progress of the groups (only one group reported problems within the group during the study), to evaluate their tasks and to collect their feedback at the end of the study, using the questionnaire. Students had to prepare the presentations of their assignments using an online collaborative tool, Prezi, whose education licence is free of charge.

\subsection{Instrument}

After three weeks of collaborative work, students presented their work and reported their opinions through an anonymous questionnaire. The questionnaire had three parts: first there was general demographic information (gender, region, school, internet access); the second part was devoted to the use of social media in general, and the third part was on the collaborative work. Statements formed key variables (constructs) researched in the study: general experiment quality, motivation, self-management of the group, trust, conflicts, absence of formal facilitation and structure, group satisfaction, and user experience, and agreement to the statements were measured on a five-point Likert scale ranging from 1-strongly disagree, 2-disagree, 3-non decisive, 4-agree, to 5-strongly agree. The reliability of the instrument was examined by analysing internal consistency and the correlation matrix. Two basic constructs, self-management of the group and the absence of structure and facilitation, and their association to motivation, trust and conflicts within the group will be analyzed in the following text.

(C1) Self-management of the group was measured by four statements and their reliability $(a=.815)$. Self-management of the group is directly connected to the basic assumption of the paper: groups form freely, are more coherent and the work load delegation is equal among members. A score of 1 means that members strongly disagree that the group effectively managed itself, and a score of 5 means that members strongly agree that the group was able to organize itself.

S1: We have immediately assigned roles in the group.

S2: We have assigned the leader of the group with consensus.

S3: The group was coherent.

S4: The work was delegated equally between the group members.

(C2) Formal structure and facilitation was measured by three statements. Reliability was measured by Cronbach's alpha $(\mathrm{a}=.794)$.

Statements were calculated into a new variable where Score 1 on the scale means that respondents strongly disagree that the formal structure and facilitation helps the group work and Score 5 means that respondents strongly agree that formal structure and facilitation would have helped the group work.

S5: Facilitation and guidance of the group would contribute to better work of the group.

S6: Formally enforced structure and roles within the group would help the group work more efficiently.

S7: I missed formal structure, rules and facilitation.

(C3) Motivation

S8: I was motivated for problem solving.

(C4) Trust

S9: I believed that my colleagues would complete their part of the assignments.

(C5) Conflicts

S10: There were conflicts within the group during the experiment.

(C6) General experiment quality 
S11: The experiment was well prepared.

S12: Time for problem solving was appropriate.

(C7) Group satisfaction

S13: Group work contributed to effective research of the problem.

S14: The group performed better than everyone would by his/her self.

(C8) User experience

S15: Virtual environment contributed to personal involvement.

S16: Virtual environment contributed to problem solving.

S17: The experiment attributed to better quality of the course.

\subsection{Hypotheses}

Our assumptions were based on the idea that in the social media environment the group efficiently organizes itself and that members feel no discomfort from the absence of facilitation and formal structure. Therefore, the stated hypotheses aim to test the associations between the perceived role of formal structure and facilitation in group work to self-management of the group and to motivation, trust, and conflicts. Furthermore, the association between self-management of the group to motivation and trust are being evaluated. Based on the theoretical background we designed the following hypotheses:
(H1) Formal structure and facilitation in collaborative problem solving is associated to self-management of the group.

(H2) Motivation and self-management of the group are positively associated.

(H3) Trust is positively associated with self-management of the group.

(H4) Trust is positively associated with formal structure and facilitation.

(H5) Conflicts within the group are associated to formal structure and facilitation.

To test the stated hypotheses, we performed basic descriptive and correlation analysis in SPSS. Hypotheses were tested on a $\mathrm{p}<.05$ level of confidence.

\section{Findings}

There were 24 subjects aged between 20 and 23 (78.3\% male and $21.7 \%$ female) participating in the study. Nineteen students came from the Gorenjska region, three from the central Slovenia region, one from the Koroška region, and one from Serbia. Sixteen of the students finished technical secondary school, three of them academic secondary school and three of them healthcare secondary school. All except one have their own computer or laptop, and all except one had broadband access to the internet. The majority of the students $(83 \%)$ reported having access the internet via their mobile phone. On average, they have more than one e-mail addresses.

The second part of the questionnaire addresses the social media usage among subjects. The results show that $29 \%$ of

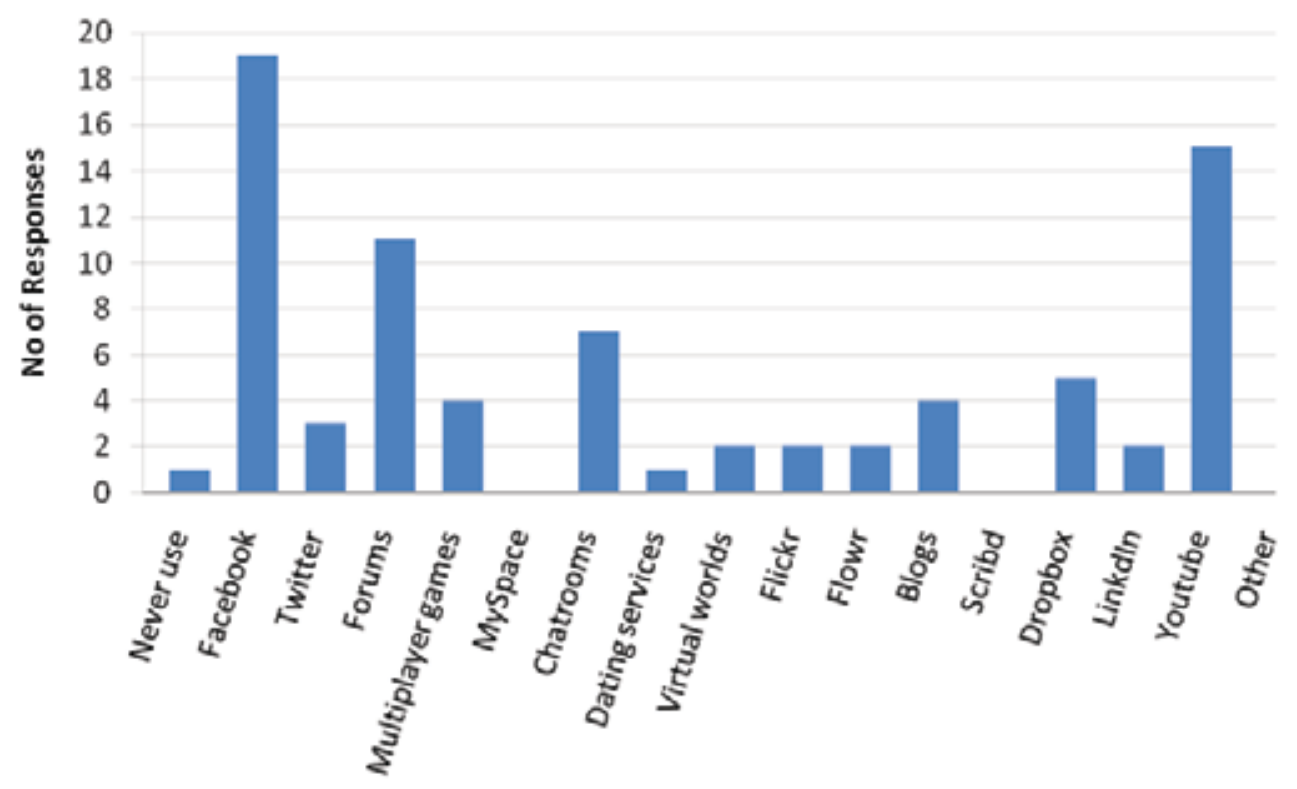

Type of Social Media

Figure 1: The use of Social Media among respondents 
the respondents browse the internet up to one hour per day, $25 \%$ reported browsing up to two hours daily and almost $42 \%$ browse more than two hours per day; A total of $25 \%$ of the respondents reported to 'not think about' the issues of trust in relation to the social media use; $37 \%$ reported being 'cautious', almost $17 \%$ reported to 'trust people, not services', and almost $21 \%$ 'don't trust' these services at all. Among respondents, $12.5 \%$ reported to use the web for studies 'moderately' (in half of the courses), 37.5\% reported to use the web for studying 'frequently' in more than half courses, and $50 \%$ of the respondents stated that they always use web resources.

In Figure 1, we present the reported use of various Social Media by the study participants. From Figure 1, we can observe that Facebook and YouTube, followed by the forums, are predominantly used by students. Very few reported using Twitter, Flickr, Scribd, LinkedIn, which are considered to cover more professional and specialized contents. When asked what they expect of an e-learning environment, the majority of respondents stated that a forum was a first priority, followed by chat rooms (with the possibility of chatting to professors), online examination, literature repository, and at the end of priority list were the wikis, blogs, and interactive and animated contents, which are considered to enhance the collaborative and reflective learning.

Further, only two of the respondents reported having known about the social service Flowr prior to this study. On average, respondents reported the usefulness of Flowr to be average $(M=2.71, S D=0.99)$ and the ease of use to be average $(M=3.29, S D=1.19)$. They also reported some issues with the service operation (problems in group communication, multiple posting of comments, problems with group assigning - repeated group authentications).

The third part of the questionnaire was devoted to study the participants' opinion about collaborative learning in the social media environment. The subjects opinion on eight sets of variables were examined: (C1) self-management of the group, (C2) formal structure and facilitation, (C3) motivation,
(C4) trust, (C5) conflicts, (C6) experiment quality, (C7) group satisfaction and (C8) user experience.

Table 1 presents the frequencies of subjects responses in percentages of respondents' level of agreement (from 1 strongly disagree to 5 - strongly agree) grouped into eight variables $(\mathrm{C} 1-\mathrm{C} 8)$, which were computed from subsets of questions, along with the basic descriptive statistics ( $\mathrm{M}$ and $\mathrm{SD})$.

From Table 1, we present eight variables that were derived from the statements described in Section 2.1. The majority of respondents agreed that the general quality of the experiment was good. They agreed (reported four or more points on the 5 -point scale) that they were motivated for the work $(60.87 \%)$. More than $80 \%$ agreed that group had sufficiently self organized, i.e. members assigned roles, leadership and workload easily. Agreement on trust among members was assessed as good by more than $80 \%$ of respondents, while $66.67 \%$ of the respondents stated there were no conflicts in the group. Only $4.17 \%$ reported strong agreement and $16.67 \%$ reported agreement to the statement that there were conflicts within the group. This corresponds to the reports of conflicts within one group during the experiment, which led to the one group member transition to another group. A mere $8.33 \%$ strongly agreed and $37.5 \%$ agreed that facilitation and structure would contribute to better group work; $45.83 \%$ were neutral on this and only $8.34 \%$ disagreed on this. The vast majority of the respondents (more than 88\%) reported that they were satisfied with the work of the group. Further, as seen in Table 1, 45.83\% of respondents reported neutral opinions about the user experience, half of them agreed to having had good user experience, while none reported negative user experiences.

\subsection{Hypotheses testing}

(H1) Formal structure and facilitation in collaborative problem solving is associated to self-management of the group. $\left(r_{S} \neq 0\right)$.

Table 1: Subjects responses on 8 variables $(N=24)$

\begin{tabular}{lrrrrrrrr} 
& 1 & 2 & 3 & 4 & 5 & Total & M & SD \\
\hline C1 & & 4.17 & 12.50 & 33.33 & 50.00 & 100 & 4.10 & 0.89 \\
C2 & 4.17 & 4.17 & 45.83 & 37.50 & 8.33 & 100 & 3.42 & 0.88 \\
C3 & & 8.70 & 30.43 & 43.48 & 17.39 & 100 & 3.70 & 0.88 \\
C4 & 4.17 & & 12.50 & 37.50 & 45.83 & 100 & 4.21 & 0.98 \\
C5 & 66.67 & 4.17 & 8.33 & 4.17 & 16.67 & 100 & 2.00 & 1.55 \\
C6 & & 4.17 & 20.83 & 45.83 & 29.17 & 100 & 3.75 & 0.71 \\
C7 & & 4.17 & 8.33 & 50.00 & 37.50 & 100 & 4.00 & 0.82 \\
C8 & & & 45.83 & 50.00 & 4.17 & 100 & 3.64 & 0.51 \\
\hline
\end{tabular}

*Scores on a 1-5 point Likert scale 
A Spearman rank order correlation was calculated to assess the relationship between the amount of formal structure and roles and the ability of the group to self-manage. The results revealed that there is moderate negative correlation between the formal structure and facilitation and self-management of the group $\left(r_{s}=-.483, p=.017\right)$. In other words, less facilitation and structure is associated with greater ability to self-manage.

$(\mathrm{H} 2)$ Motivation and self-management of the group are positively associated. $\left(r_{S} \neq 0\right)$.

A Spearman test was performed and the results revealed that there is significant positive correlation between motivation and self-management of the group $\left(r_{s}=.555, p=.006\right)$. Increase in motivation is associated with an increase in the ability of the group members to effectively self-organize.

(H3) Trust is positively associated to self-management of the group. $\left(r_{s} \neq 0\right)$.

A Spearman test was performed and the results revealed that there is significant positive correlation between trust and self-management of the group $\left(r_{s}=.455, p=.026\right)$. A higher sense of trust is positively associated with an increase in the ability of the group members to effectively self-organize.

(H4) Trust is positively associated with formal structure and facilitation. $\left(r_{s} \neq 0\right)$. The Spearman rank order was calculated to assess the association between trust and formal structure and facilitation. The results revealed that there is no correlation between trust and formal structure and facilitation $\left(r_{s}=.177, p=.408\right)$. Findings suggest that perceived trust is not related the amount of formal structure and facilitation.

(H5) Conflicts within the group are associated to formal structure and facilitation. $\left(r_{s} \neq 0\right)$. A Spearman test was performed and the results revealed that there is significant moderate negative correlation between conflicts and formal structure and facilitation $\left(r_{s}=-.474, p=.019\right)$. An increase of conflicts within group is associated with the decrease in the amount of formal structure and facilitation.

\section{Discussion and conclusion}

The results of the study suggest that formal structure and facilitation is negatively associated with the self-management of the group, which encompasses the assigning of roles, leadership, and coherency of the group and workload delegation (H1). Less facilitation and structure is associated with a greater ability to self-manage. This implies that the rule-free and unstructured environment with no guidance foster conditions in which participants are more willing to self organize. However, we should be careful with this conclusion for two reasons. Firstly, the number of participants was very small and secondly, according to the descriptive statistics, $45 \%$ of the respondents reported neutral opinions about the role of facilitation and structure in the collaborative work.

Furthermore, self-management of the group is associated to both trust and motivation $(\mathrm{H} 2, \mathrm{H} 3)$, which is in line with many studies stating that trust and motivation are essential in self organizations of the groups in the social media environment (Rosen, 2007, Hafkesbrink \& Evers, 2010). However, trust is very complex and can be studied from various perspec- tives (interpersonal, philosophical, and organizational). In this study, we have only studied trust as perceived by individual group members. The results that suggest that trust is not associated with formal structure and facilitation are somewhat surprising (H4). This means that the absence of guidance, structure and rules would not affect how group members perceive trust or vice versa. What influences the perceived trust in the collaborative environment of a social media would need to further research. Furthermore, examining how conflicts are related to formal structure and facilitation, the results suggests that with the increase of conflicts within group the formal structure and facilitation decreases. This implies that guidance and structure are regarded as not being helpful in a conflict situation.

Some insight in the student's readiness to use the social media is provided in the second part of the questionnaire. Respondents reported they still perceive forums and chat rooms to be more important than knowledge creation tools, such as wikis and micro blogs, in terms of the virtual learning environment. Although students have reported that the social media approach in this study contributed to the course execution and to positive learning experience, they identify the possibility of chatting with the teacher as one of the priorities in an on-line learning environment. This supports the findings of Kim (2010), who suggested that the teacher in fact assumes the role of a facilitator. The inability of the students to identify other services as having learning potential promotes the still greater role of the teacher. Therefore, special attention should be put on teaching about the use of social media tools in the virtual learning environments.

This study has explored and described the potential of social media for educational purposes and especially in collaborative problem solving and reflective learning support. Classic in-class and virtual learning environments can be effectively enhanced with the use of social media, bearing in mind factors like process facilitation, a well-prepared assignment that not only motivates the students but also enhances their group experience. The drawback of this research lies in the small number of subjects. Future research on collaborative problem solving should be focused on rigorous experimental design for studying the participants' behaviour and performance. The results of this study show some promising directions for further studies on how people use social media in self organizing groups for problem solving, especially in education where the research approach is more of relevance and the rigor is usually lagging behind.

\section{Acknowledgement}

This research was funded by the Ministry of Higher Education, Science and Technology of the Republic of Slovenia; Program No. P5-0018.

\section{Literature}

Barabási, A. (2002). Linked: The science of networks. Cambridge, MA: Perseus Publishing 
Beckman, M. (1990). Collaborative Learning: Preparation for the Workplace and Democracy, College Teaching, 38(4), pp. 128133.

Collier, K. G. (1980). Peer-Group Learning in Higher Education: The Development of Higher-order Skills, Studies in Higher Education, 5(1), pp. 55-62. DOI:10.1080/0307507801233137 7306

Cooper, J. (1990). Cooperative Learning and College Teaching: Tips from the Trenches, Teaching Professor, 4(5): 1-2.

Dillenbourg, P. (1999). Collaborative Learning: Cognitive and Computational Approaches. In Advances in Learning and Instruction Series, Dillebourg P. (ed). Elsevier Science, Inc., New York.

Dubois, D. M. (2010). Breakthrough in the Human Decision Making Based on an Unconscious Origin of Free Will, ACTA SYSTEMICA, Vol. X(1): 13-18.

Fiechtner, S. B. \& Davis, E. A. (1992). Why Some Groups Fail: A Survey of Students' Experiences with Learning Groups, In: A. Goodsell, M. Maher, V. Tinto, and Associates (eds.), Collaborative Learning: A Sourcebook for Higher Education. University Park: National Center on Postsecondary Teaching, Learning, and Assessment, Pennsylvania State University.

Fjermestad, J. (2004). An analysis of communication mode in group support systems research, Decision Support Systems, 37(239263). DOI: 10.1016/S0167-9236(03)00021-6

Freire, P. (2000). Pedagogy of the oppressed (M. Bergman Ramos, Trans.), New York: Continuum International Publishing Group.

Garrison, D. R., Anderson, T., \& Archer, W. (2000). Critical inquiry in a text-based environment: Computer conferencing in higher education. The Internet and Higher Education, 2 (2-3): 1-19. DOI: $10.1016 /$ S1096-7516(00)00016-6

Hafkesbrink, J. \& Evers, J. (2010). Innovation 3.0 - Embedding into community knowledge: the relevance of trust as enabling factor for collaborative organizational learning. In: Hafkesbrink, J., Hoppe, H.-U. \& Schlichter, J. Competence Management for Open Innovation - Tools and IT-Support to Unlock the Potential of Open Innovation, Eul Verlag.

Hale, R., \& Whitman, P. (1997). Practical Problem Solving and Decision Making. Kogan Page: London.

Hsiao, N., \& Richardson, G. P., (1999). In search of theories of dynamic decision making: a literature review. In 17th International Conference of the System Dynamics Society, Wellington, New Zealand. Retrieved February 19, 2012, from http://www.systemdynamics.org/conferences/1999/PAPERS/ PLEN16.PDF

Khalifa, M., Davison, R., \& Kwok, R. C. W. (2002). The effects of process and content facilitation restrictiveness on GSS mediated collaborative learning. Group Decision and Negotiation, 11: 345-361. DOI: 10.1023/A:1020449317854

Kim, Y. (2010). Supporting distributed groups with group support systems: a study of the effect of group leaders and communication modes on group performance. In Strategic Information Systems: Concepts, Methodologies, Tools, and Applications, Hunter MG (ed.). Hershey, PA: Information Science Reference; 1559-1572.

Kljajić Borštnar, M., Kljajić, M., Škraba, A., Kofjač, D., \& Rajkovič, V. (2011). The relevance of facilitation in group decision making supported by a simulation model, System Dynamics Review, 27(3): 270-293. DOI: $10.1002 / \mathrm{sdr} .460$

Kreijns, K., Kirschner, P. A. \& Jochems, W. (2003). Identifying the pitfalls for social interaction in computer-supported collaborative learning environments: a review of the research. Computers in Human Behavior, 19(3), 335-353. DOI: 10.1016/S07475632(02)00057-2

Limayem, M., Khalifa, M. \& Ma, S. (2002). Human versus automated facilitation in the GDSS context. In Proceedings of the 2002 IEEE International Conference on Systems, Man and Cybernetics, Vol. 5: Hammamet, Tunisia, 6-9 October.

Lizeo, E. (2005). A Dynamic Model of Group Learning and Effectiveness, System Dynamics Society Conference 2005, Boston, USA.

Minocha, S. (2009). An empirically-grounded study on the effective use of social software in education, Education and Training, special double issue on Computer Assisted Collaborative Learning: The New Generation of Simulations and Social Computing in the Business Curriculum, 51(5/6): 381-394. DOI: 10.1108/00400910910987192

Potter, A., McClure, M., \& Sellers, K. (2010). Mass collaboration problem solving: A new approach to wicked problems. 2010 International Symposium on Collaborative Technologies and Systems, 398-407. DOI: 10.1109/CTS.2010.5478486

Rosen, E. (2007). The Culture of Collaboration: Maximizing Time, Talent and Tools to Create Value in the Global Economy, Red Ape Publishing.

Rouwette E. A. J. A. , Größler, A., \& Vennix, J. A. M. (2004). Exploring influencing factors on rationality: a literature review of dynamic decision making studies in system dynamics. Systems Research and Behavioral Science, 21(4): 351-370. DOI: $10.1002 /$ sres.647

Simon, H.A. (1991). Bounded Rationality and Organizational Learning, Organization Science Vol. 2, No. 1, Special Issue: Organizational Learning: Papers in Honor of (and by) James G., pp. 125-134.

Škraba, A., Kljajić, M. \& Leskovar, R. (2003). Group exploration of system dynamics models: is there a place for a feedback loop in the decision process? System Dynamics Review, 19: 243-263. DOI: $10.1002 /$ sdr.274

Škraba, A., Kljajić, M. \& Kljajić Borštnar, M. (2007). The role of information feedback in the management group decision making process applying system dynamics models. Group Decision and Negotiation, 16: 77-95. DOI: 10.1007/s10726-006-9035-9

Tapscott, D. \& Williams, A.D. (2006). Wikinomics: How mass collaboration changes everything. New York: Penguin.

Wang, H. (1997). Knowledge level analysis of group decision support systems. Expert System with Application, 13: 155-162. DOI: 10.1016/S0957-4174(97)00016-X

Wells, G., (1999). Dialogic Inquiry. Cambridge: Cambridge University Press.

Mirjana Kljajić Borštnar holds a Ph.D. in Organizational Sciences from the University of Maribor. Her research work covers expert systems, multi-criteria decision-making, and Information Systems development methods. She holds a position of an Assistant Professor and is a member of Laboratory for Decision Processes and Knowledge-Based Systems. Her recent research work is focused on experiments with decision groups applying system dynamics simulators in experimental, real and interactive learning environments. She is the author and co-author of several scientific articles published in recognized international journals including Group Decision and Negotiation and System Dynamics Review. 


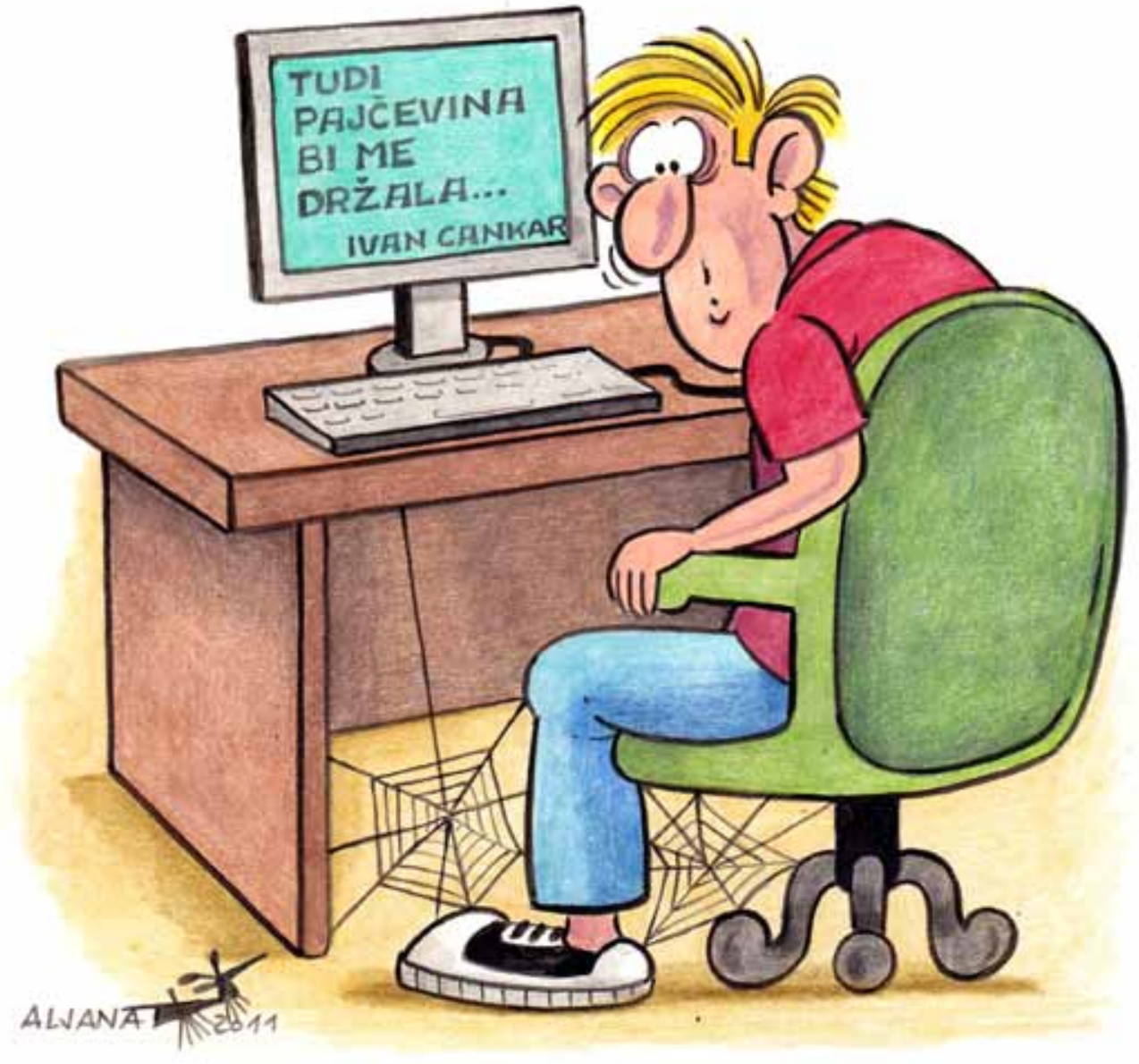

